this condition have been treated at Westminster Hospital with one death, a lady aged 92, who died subsequently of multiple liver abscesses.

I therefore had considerable backing for the plea that hyperbaric oxygen should be used in this condition. In my second letter I gave a further reason for listing the chambers available, which was so that other conditions, notably gas gangrene, might be treated promptly. Drs. Matthew and Proudfoot placed a full stop (in more ways than one) after "carbon monoxide poisoning" when quoting my letter, where I had written "carbon monoxide poisoning, gas gangrene infections, etc."

Finally, there are no attendant risks of oxygen poisoning to doctors and nurses in single-patient oxygen chambers which constitute 26 out of 29 chambers listed in my letter. May I respectfully suggest that doctors, ambulance workers, and police may still feel constrained to rush patients with carbon monoxide poisoning to centres, where hyperbaric facilities are available?-I am, etc.,

Westminster Hospital, JoHN THURSTON.

London S.W.1.

REFERENCES

Ledingham, I. McA., in Modern Trends in Pharmacology and Therapeutics, edited by W. F. M. Fulton, 1967, p. 96. Butterworths,

Ledingham, I. McA., Lancet, 1968, 1, 77

Smith, G., Practitioner, 1966, 197, $553,1,398$

\section{Prevention of Coronary Disease}

SIR,-I agree with your correspondent Dr. R. Mulcahy (18 January, p. 180) in advocating the beginning of a public health programme for diminishing coronary disease, though I fear that nothing less than a profound change in our national mores will have any significant effect.

The thread that binds all the known aetiological factors in this disease is the way-oflife of the patient, which epitomizes many of the worst features of our disorderly western civilization. The number of people who live serene, rhythmic, slow tempo, non-competitive lives and develop coronary disease is very small. Most experienced general practitioners know very well that the kind of life a man leads is very closely related to the diseases he develops, and the wise ones in their own practices can help those patients whose lives are pursuing a self-destructive course.. If we cannot do much as a profession to reorientate our national life, we can make a small beginning in advocating the establishment of screening techniques which will combine our knowledge of known aetiological factors with the personal knowledge family doctors have of their patients.-I am, etc.,

Leeds. Alastair U. Mackinnon.

\section{Leukaemia and the Rheumatic Diseases}

SIR,-The suggestion of an association between the leukaemias and reticuloses and the rheumatic diseases ${ }^{13}$ has been widely quoted but has not been confirmed. We have therefore studied this question by reviewing the histories of 363 adults with leukaemia or allied disorder registered during 1959-63

with the Cancer Council of Western Australia. Eighteen per cent. of these patients had a previous history of a rheumatic condition. Although we were unable to obtain a satisfactory control population, we believe the incidence of rheumatic disorders in Western Australia to be similar to the $20 \%$ reported in Sydney by Nelson and Lancaster, ${ }^{3}$ where climatic and socio-economic factors are similar. The incidence of rheumatic disorders reported from other countries ranges from $25 \%$ to $64 \%$ of the population.

Figures from Western Australia, therefore, do not support an association of the leukaemias and reticuloses with the rheumatic diseases. The findings of a rheumatic condition in $8.8 \%$ of leukaemia patients by Abbatt and Lea is not surprising ; what is surprising is the very low $3.8 \%$ incidence of rheumatic

\title{
Administrative Structure of the N.H.S.
}

SIR,-I am in general agreement with many of the recommendations of Council about reorganization of the National Health Service (Supplement, 28 December, p. 77), but there are one or two points which I fail to understand.

The first is the unwillingness to have any local government participation. We forget, perhaps, that the local authorities represent the community-that is, the patients-and they are surely entitled to have a say in what kind of service the local community needs. Looking back, one should remember that both the London County Council and the Middlesex County Council were building up an excellent hospital service until further development was prevented by the war. Let us remember, too, that after the first world war St. James's Hospital, Balham, gave Gillies beds when no other hospital in London would do so, thus allowing for the development of

\section{Vocational Training for General Practice}

SIR,-Perhaps we might pause for a moment, in the light of the increasing possibility that extensive vocational training for general practice may soon become a compulsory reality, to look at what the Royal College of General Practitioners has achieved over the last three years since the inception of this concept of five years' postgraduate training schemes for young graduates intending to practise N.H.S. general practice.

Firstly, it will encourage young doctors to stay longer in hospital junior appointments before they make up their minds on the specialty of their choice, and increases the likelihood of their staying in a hospital career. This means that all newly qualified doctors will be forced to endure longer financial hardship, the necessary residencies of junior posts, be discouraged from marrying, and their availability to general practice at a time when the N.H.S. is already short will be delayed.

Secondly, and to add more disincentives, the College has restricted full membership to entrants by examination only, so that at the end of this exhaustive training the candidate may still be categorized as an inadequate failure at the age of 30 or more. This is also difficult to understand in view of the recent discussions the College has been having about examination methods-in particular, their variability and unsuitability in the prope assessment of the complex task of judging diseases in their control population. This suggests that they were dealing with a selected group and that their conclusions do not have general validity.-We are, etc.,

\section{G. M. LeAveSLEY}

Department of Haema tology,

Woyal Perth Hospital,

L. Dougan.

Cancer Council of Western Australia.

Department of Haematology,
Royal Perth Hospital.

H. J. WoOdLIFF. Royal Perth Hospital
Western Australia.

REFERENCES

Abbatt, J. D., and Lea, A. J., Lancet, 1958, 2, 880 .. J., Ann. rheum. Dis., 1964, 23, 480. elson, S. G., and Lancaster, H. O., Med. F.

plastic surgery in this country. This hospital, too, at that same time, also started the first fracture unit in the country.

The second point I do not understand is the statement, "A large number of area boards might lead to the needs of teaching and research being subordinated to the dayto-day needs of the hospitals." This is indeed putting the cart before the horse. The day-to-day needs of the hospital-that is, the ordinary treatment of ordinary patients-is what the average hospital is there for. Teaching and research, important though they be, must inevitably be subordinated to the dayto-day needs of any hospital, and I am sure that the vast majority of taxpayers, who finance us, would not have it otherwise.-I am, etc.,

\section{Newton Abbott, A. RoBinson THOMAS} Devon.

doctor's competence. What a pity the College did not hold the discussions before they introduced the retrogressive principle of formal examination, about which even the Royal Commission on Medical Education has grave misgivings. To add further confusion, until July 1968 the College allowed and even later encouraged the older general practitioner to enter with full membership on the grounds only of long experience. So it would seem that it still believes that experience is a valid substitute for formal training presumably, or was it to avoid the embarrassment of failing a senior colleague ?

Thirdly, as pure experience and satisfactory service no longer guarantee the associate member full membership after a definite period, there would seem to be very little advantage any longer to being an associate of the College, particularly as my own subscription has recently been increased by $150 \%$, so that it now exceeds my contributions to the B.M.A. and the M.D.U. combined.

Fourthly, let me say that I have put all these points to the Board of Censors of the Royal College of General Practitioners, and have not had satisfactory justification of these decisions. I have been told that the great majority of members now favour examination, thus relating it to other branches of medical practice, as it constitutes a test of competence 